\title{
Proximal Phalanx of Hand
}

National Cancer Institute

\section{Source}

National Cancer Institute. Proximal Phalanx of Hand. NCI Thesaurus. Code C52786.

One of five small bones located in the hand that form the base of each finger, and that articulates proximally with the head of a metacarpal bone. 